Unamuno, con el recio ejemplo de su vida y obra, es un grito perenne de protesta contra los innúmeros Maeztus del instante.

Encomiable labor, pues, la de todos los escritores que fijan en estas biografías aquellas siluetas de bronce en que vive la pureza intelectual de la Península: un Unamuno, un Valle Inclán, un Ossorio y Gallardo, un Marañón o un Reparaz.-Ricardo A. Latcham.

\section{San Agustín, por Luis Bertrand.}

Las fiestas con que en el mundo entero se ha conmemorado el XV aniversario del fallecimiento de San Agustín han puesto nuevamente de de actualidad el libro que hace algunos años dedicó al santo africano Luis Bertrand, para quien los personajes religiosos han tenido siempre una seducción especial.

La figura de San Agustín cobra, día a día, un interés mayor, y cualesquiera que sean las creenciac toda persona que se interese por los prolemas de la cultura ha de sentirse $h$ specialmente atraída por quien en a antigüedad romana, que moría , entamente, fué uno de los individuos más cultos, un defensor entusiasta 'de la cultura, y en el seno de la Ig leșia a que pertenecía, uno de los pensadores más profundos. Por esto encontramos plenamente justificado el interés de Bertrand por San Agustín, que es una figura de actualidad permanente.

El libro que le ha consagrado es curioso e interesante. Curioso, porque cuesta clasificarlo en un género determinado $\mathrm{No}$ es una biografia en el rigor de la palabra; tampoco es una biografía novelada, ya que los datos de rigor histórico faltan por completo en el libro, como las fechas en que se desenvuelve; tampoco podría afirmarse que es un estudio sobre la vida y el pensamiento del santo, por cuanto no se ha estudiado el pensamiento agustiniano en su integridad, ni tampoco la influencia que tuvo en la antigüedad cristiana; a lo sumo podríamos decir que es la interpretación actual, que un francés de este siglo da al fenómeno curioso que en la historia del pensamiento antiguo es San Agustín. Y reside el principal interés del libro en la interpretación a que hemos aludido, de carácter principalmente poemático, en algunos pasajes, lo que presta al volumen de Bertrand un especial encanto. Pero la fluidez del estilo, la elevación y seriedad con que el tema está tratado, y más que todo, la permanente solidez de la evocación del santo, que son, a nuestro juicio, las cualidades primordiales de la obra de Bertrand, se hallan completamente desvirtuadas en la traducción castellana, por la pésima calidad de ésta. El traductor un señor Lapuya, desconoce por completo el arte de traducir, arte secundario si se quiere, pero arte al fin. Premunido de conocimientos de francés que no parecen ser muy profundos, se ha lanzado a una empresa difícil, y para salir del paso emplea el sistema de traducción literal, con diccionario en mano, que le hace caer en renuncios notorios. Así el primer capítulo Un municipio afri cano, tiene muy poco de Bertrand 
y sí mucho del galimatías del señor Lapuya, galimatías que evidentemente no nos interesa. También se encuentran palabras inventadas que no pertenecen al francés ni al castellano, y que son galicismos burdos.

Es sensible que un mal traductor pueda echar a perder una obra de interés como la que comentamos, pues en el original francés que hemos releído en la Revue des Deux Mondes, que lo publicó hace algunos años, Bertrand consiguió una interpretación, ni muy acertada ni muy profunda, de San Agustín, que, por sus condiciones de estilo, sobrio, armónico y de una suprema elegancia, llegaba a todos los corazones aunque no haría pensar a muchas cabezas, porque el elemento ideológico del libro no es lo principal.

Hoy día, la circunstancia que hemos indicado al comenzar esta crónica, pone de nuevo en actualidad el libro de Bertrand, que es el más adecuado para difundir el conocimiento de San Agustín entre toda la gente que se interesa por adquirir conocimientos de ocasión o circunstanciales. Pero sin duda alguna, es una obra con mala suerte, pues agotadas las ediciones francesas sólo han llegado a las librerías los ejemplares de la traducción a que nos hemos referido, y que no hace ningún favor ni al santo, $\mathrm{ni}$ al autor.-Abel Valdés $A$.

\section{Mariátegui, por Eugenio Orrego Vicนña.}

La tragedia de la presente generación sudamericana es la tragedia de una generación sin maestros. ¿Han producido la Universidad, la política, el ejército, la literatura una personalidad ejemplar $y$ señera que se aureolara de la confianza colectiva y condujera a las multi tudes a la realización de un gran ideal? La respuesta negativa parece imponerse.

Han sido malos años los nuestros. El cambio operado ha sido tan violento y profundo que las rupturas surgidas del desastre no podían admitir parches más o menos generosos aconsejados por arbitristas entusiastas. Pudo existir acaso la madera del gran espíritu. Pero, sofocado en medio de la hostilidad o la indiferencia de sus contemporáneos, prefirió hundirse en la soledad $y$ en el silencio a construir orgullosamente la propia obra.

Y esa conciencia de la obra bien hecha, esa dignidad del oficio que ha mantenido en un egoísmo saludable a tantoc espíritus que no han querido afrontar las asperezas de la lucha, ha sido la salvación de ellos mismos y de sus contemporáneos que han podido ser los testigos apasionados de sus meditaciones.

No es precisamente el caso de José Carlos Mariátegui que con tanta simpatía estudia Eugenio Orrego Vicuña en su conferencia recogida ahora en libro (1).

Mariátegui desafió virilmente el medio hostil y fué el abanderado de todo un movimiento de renovación social. Pudo haber sido el maestro de su generación. Pero las

(1) Ediciones Mástil, Santiago de Chile, 1930. 